\title{
USO E COBERTURA DA TERRA NA CAMPANHA OCIDENTAL DO RIO GRANDE DO SUL: UMA ANÁLISE TEMPORAL A PARTIR DE DADOS ORBITAIS DE MÉDIA RESOLUÇÃO ESPACIAL
}

\author{
Emanuel Araújo SILVA \\ Juliana TRAMONTINA ${ }^{2}$ \\ Elisiane $A L B A^{2}$ \\ Eliziane Pivoto MELLO² \\ Rudiney Soares PEREIRA² \\ Laura Camila de Godoy GOERGEN³
}

\section{Resumo}

As microrregiões de Campanha Ocidental, no sudoeste do Rio Grande do Sul, vêm sofrendo ao longo do tempo com o processo chamado de arenização, que é intensificado devido as expansões de soja, arroz e pastoreio, propiciando a degradação da paisagem. Compreender o processo dinâmico de transição das classes de uso e cobertura da terra é fundamental para monitorar tal processo na região Sudoeste do Rio Grande do Sul. O objetivo desse estudo foi identificar e quantificar os padrões de uso e cobertura da terra que recobrem as microrregiões da Campanha Ocidental no Rio Grande do Sul, por meio da análise temporal de imagens com média resolução espacial. Imagens Landsat 5 e 8 foram utilizadas para o mapeamento temático do uso e cobertura da terra para os anos de 1985, 1996, 2011 e 2013 por meio da classificação supervisionada. Mapas de transição das classes temáticas foram desenvolvidos por meio da Linguagem Espacial para Geoprocessamento Algébrico. Agricultura e pecuária são as classes de uso da terra predominantemente. A classe floresta aumentou em todos os períodos analisados, enquanto a sua expansão está relacionada com a classe campo. O desmatamento teve maior influência da classe campo, seguido da agricultura.

Palavras chave: Sensoriamento remoto. Processamento de imagens. LEGAL.

\footnotetext{
1 Universidade Federal Rural de Pernambuco, Professor do Departamento de Ciências Florestais, 52171-900, Recife, PE, Brasil.E-mail: emanuel.ufrpe@gmail.com

2 Programa de Pós-Graduação em Engenharia Florestal, Núcleo de Geotecnologias - Universidade Federal de Santa Maria, 97105-900, Santa Maria, RS, Brasil. E-mail: \{tramontina.ju, elisianealba, rudiney.s.pereira\}@gmail.com; \{elizianemello\}@yahoo.com.br

${ }^{3}$ Programa de Pós-Graduação em Ciência do Solo, Universidade do Estado de Santa Catarina, 88035-001, Florianópolis - SC. E-mail: lauragoergen2@gmail.com
} 


\section{Abstract}

\section{Use and land cover in campanha ocidental of the Rio Grande do Sul: temporal analysis from orbital data of space resolution medium}

The micro regions of Campanha Ocidental, in southwest of Rio Grande do Sul, comes suffering over time with process called arenization, which is intensified due to the soy, rice and overgrazing expansions, providing the degradation of landscape. Understand the dynamic process of transition from classes of use and land cover is essential to monitor this process in Southwest region of Rio Grande do Sul. The aim of this study was identify and quantify the patterns of use and land cover which covering the micro regions of Campanha Ocidental in Rio Grande do Sul, by temporal analysis of images with medium spatial resolution. Images Landsat 5 and 8 were used for thematic mapping of the use and land cover for the years of 1985, 1996, 2011 and 2013 through supervised classification. Maps change of thematic classes have been developed through Spatial Language for Algebraic Geoprocessing. Agriculture and livestock are the classes of use land predominantly. The forest class increased in all analyzed periods, while its expansion is more related to the class field. The deforestation was most influenced by field class, followed by agriculture.

Key words: Remote sensing. Image processing. LEGAL.

\section{INTRODUÇÃO}

Com o advento da revolução industrial, o aumento do consumo de alimentos e matéria prima para a indústria provocou alterações significativas do uso e cobertura da terra. A partir disso, tornou-se perceptível o aumento das fronteiras agrícolas e expansão pecuária que, ao longo dos anos, vêm migrando do Sul para o Norte do Brasil. Tais mudanças acarretam diversos problemas inerentes a cada região que de certa forma, transforma a qualidade de vida das comunidades fragilizando sua convivência com o meio onde vivem.

Dentro desse contexto, destaca-se a microrregião da Campanha Ocidental, no Sudoeste do Rio Grande do Sul, inserida na região dos Pampas, que vem ao longo do tempo sofrendo o processo denominado arenização, o qual se intensificou em virtude da expansão da soja, do arroz e do sobrepastoreio, ocasionando a infertilidade do solo e a degradação da paisagem campeira.

Paralelamente a expansão agrícola e a arenização da região, o setor florestal diante da crise ocorrida em 2009, sofreu consideráveis mudanças. Segundo relatório da ABRAF (2012), nos últimos dez anos, a taxa anual de crescimento da área plantada no Brasil, considerando Eucalyptus e Pinus, passou por uma queda de aproximadamente 57\% em 2009 em relação a 2008. Nos anos seguintes a taxa passou a aumentar, tendo uma pequena queda de 3\% em 2012 em relação a 2011.

Nesse sentido, entender a dinâmica do processo de transição das classes de uso e cobertura da terra requer elaborar mapas temporais capazes de monitorar tais processos na região Sudoeste do Rio Grande do Sul. Os mapas temporais são resultados da classificação de imagens orbitais, apresentando grande importância em estudos da paisagem, especialmente quando se deseja analisar mudanças ao longo de um período.

Segundo Assad e Sano (1998), o processamento das informações espaciais obtidas das imagens, é um requisito para possibilitar o monitoramento automatizado 
do uso e cobertura da terra. O sensoriamento remoto, por sua vez, é uma importante ferramenta para minimizar os problemas oriundos da baixa disponibilidade de informações de campo. Kawakubo (2010) destaca a utilização do sensoriamento remoto em estudos de desmatamento e alteração do uso e cobertura da terra, visto que, é uma tecnologia que permite mapear e monitorar as transformações em grandes áreas, em intervalos relativamente curtos e a baixo custo.

O objetivo deste trabalho foi identificar e quantificar os padrões do processo de uso e cobertura da terra, as quais recobrem a microrregião da Campanha Ocidental do Rio Grande do Sul, através da análise temporal a partir de imagens orbitais de média resolução.

\section{METODOLOGIA DE TRABALHO}

A área de estudo corresponde a Mesorregião do Sudoeste do Rio Grande do Sul, onde está inserida a Microrregião da Campanha Ocidental localizada entre as latitudes 27056'37" S e 30033'41" S e entre as longitudes 54042'7" W e 57041'28" W (Figura 1).

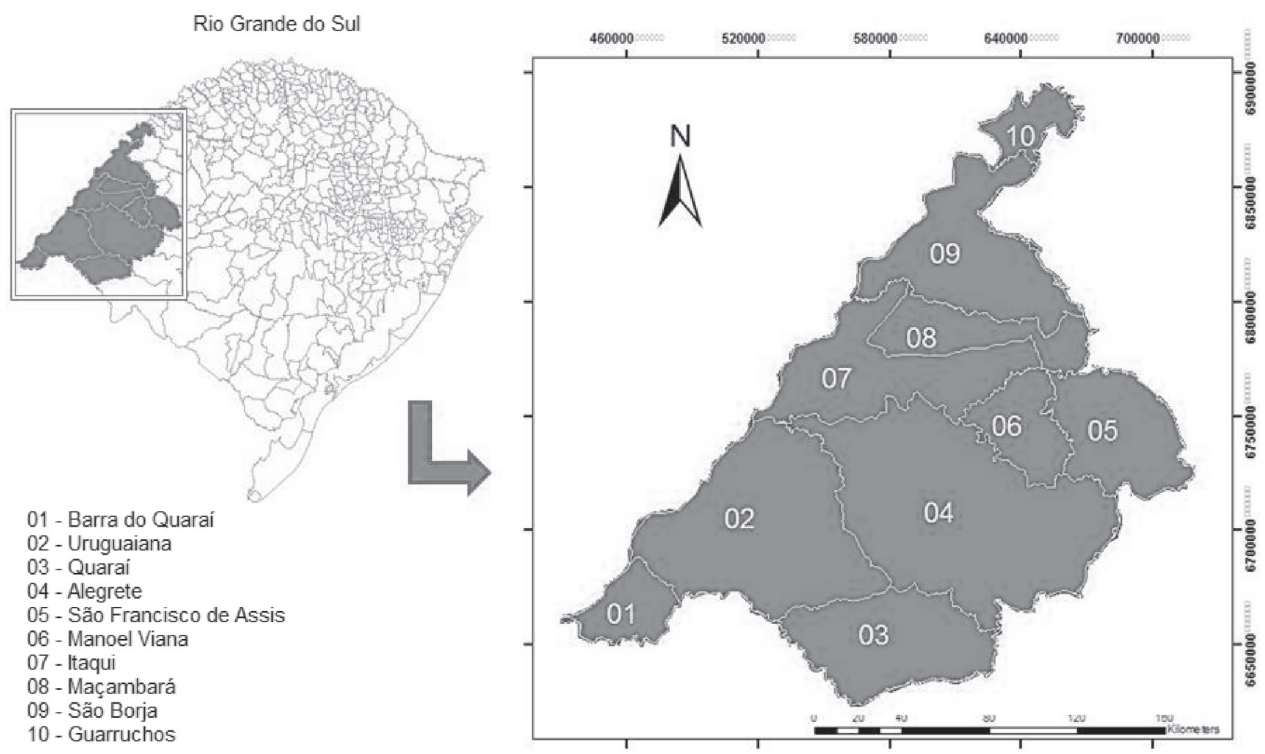

Figura 1 - Localização da microrregião da Campanha Ocidental, localizada na mesorregião do Sudoeste do Rio Grande do Sul, Brasil

O clima predominante, segundo a classificação Köppen, é do tipo Cfa, subtropical úmido, sem estação seca (MORENO, 1961). O relevo é suave ondulado com áreas planas, que contrasta com os platôs de arenito silicificado da paisagem regional (SOUTO, 1984). Geologicamente, integra a província arenítico-basáltica, caracterizando-se pelas formações litológicas do Botucatu (arenítica) e Serra Geral (basáltica) (SUERTEGARAY, 
1998). A vegetação é influenciada pelas características edáficas, com formações campestres que possibilitam cobertura escassa (ROVEDDER, 2007). Juntamente com a vegetação campestre, ocorre vegetação arbustiva. Ao longo de rios e arroios ocorre mata ciliar. Há também grandes extensões de florestas plantadas de pinus e eucaliptos.

A criação do banco de dados, e o processamentos das imagens foram realizados no Sistema de Processamento de Informações Georreferenciadas SPRING, na versão 5.2.1 (CÂMARA et al., 1996). Adotou-se para o presente trabalho projeção UTM (Universal Tranverso de Mercator) e Datum de referência WGS-1984 (World Geodetic System 1984).

Foram utilizadas imagens da série Landsat 5 e 8 . As imagens utilizadas do Landsat 5 foram adquiridas, gratuitamente, do catálogo de imagens do Instituto Nacional de Pesquisa Espacial (INPE), e as imagens do Landsat 8 foram adquiridas gratuitamente, na página do United States Geological Survey (USGS). Sete cenas que recobrem as áreas de estudo foram selecionadas para o trabalho para os anos de 1985, 1996, 2011 e 2013: órbita-ponto 223/80 de 02/04/1985, 10/06/1996, 19/05/2011 e 22/04/2013; 223/81 de 14/05/1985, 07/04/1996, 03/05/2011 e 22/04/2013; 224/79 de 11/05/1985, 16/05/1996, 24/04/2011 e 02/07/2013; 224/80 de 02/05/1985, 16/ 05/1996, 24/04/2011 e 02/07/2013; 224/81 de 03/06/1985, 16/05/1996, 24/04/2011 e $13 / 04 / 2013 ; 225 / 80$ de $10 / 06 / 1985,23 / 05 / 1996,17 / 05 / 2011$ e 20/04/2013; 225/81 de 10/06/1985, 23/05/1996, 14/03/2011 e 20/04/2013.

As imagens do Landsat 5 foram georreferenciadas utilizando-se 20 pontos de controle e adotando-se erros médios inferiores a 0,7. As imagens do Landsat 8 foram adquiridas previamente georreferenciadas. Após o registro das imagens, foi realizado o mosaico e o realce de contraste linear nas mesmas.

A classificação digital supervisionada foi executada pelo algoritmo classificador Bhattacharya, com limiar de aceitação de 99\%, onde foram identificadas e mapeadas cinco classes temáticas: Floresta, Campos, Agricultura, Areal e Água. As imagens foram segmentadas com os parâmetros de similaridade e área de 10 e 100, respectivamente.

A confiabilidade da classificação digital do uso e cobertura da terra foi avaliada por meio da matriz de confusão das áreas de treinamentos que foram classificadas aplicando-se o coeficiente de Kappa.

Os mapas de transições de uso e cobertura da terra, foram elaborados por meio da programação em Linguagem Espacial para Geoprocessamento Algébrico LEGAL, no software SPRING. Partindo dessa programação foi possível gerar dados de transição de uso e cobertura da terra para cada par de datas (1985-1996, 1996-2011 e 2011-2013.

\section{RESULTADOS E DISCUSSÃO}

\section{Mapeamento do uso e cobertura da terra}

Os mapas temáticos de uso e cobertura da terra gerados através da classificação de imagens Landsat 5 e 8, para os anos de 1985, 1996, 2011 e 2013, da microrregião da Campanha Ocidental, são representados na figura 2. 

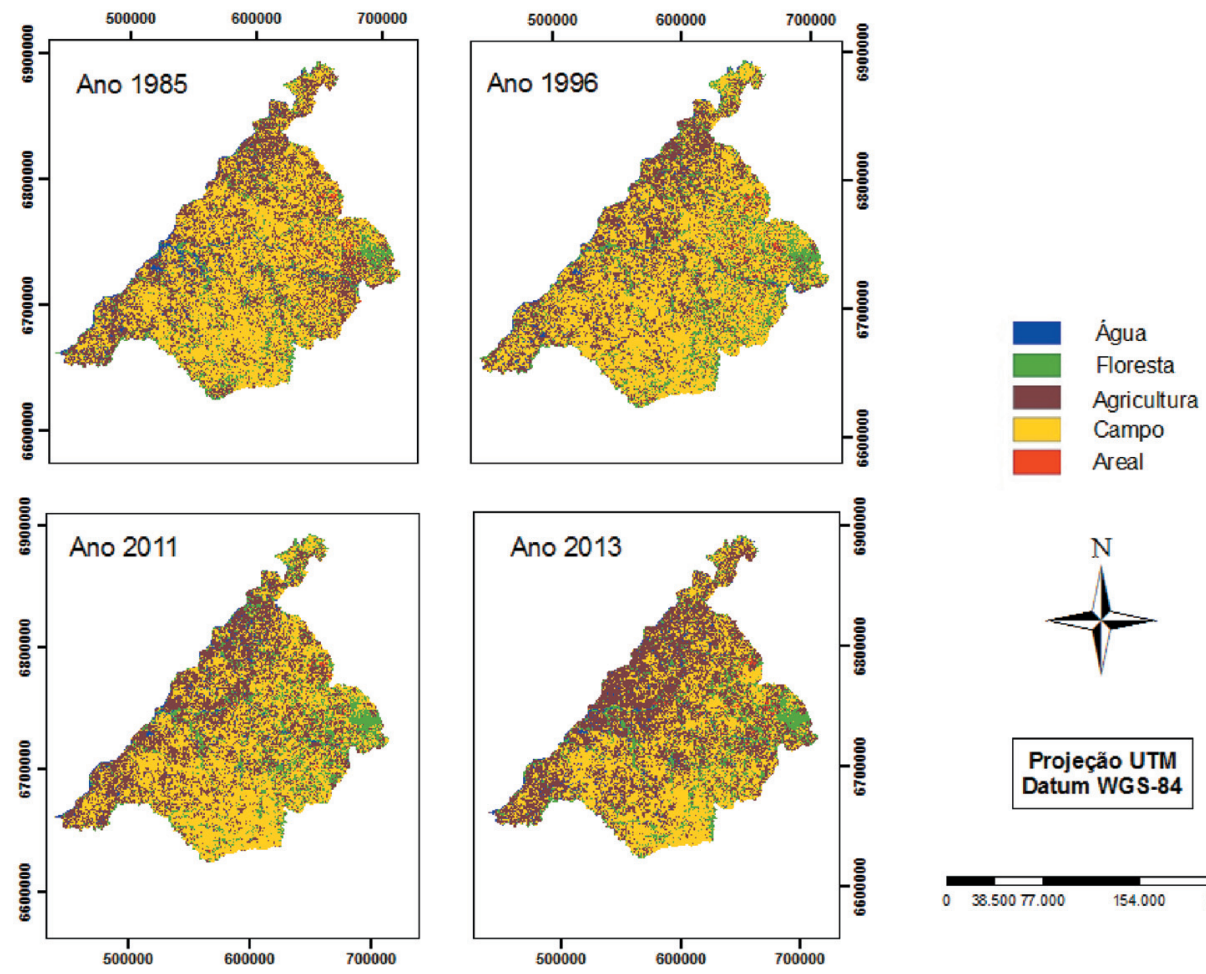

Figura 2- Mapas temáticos de uso e cobertura da terra gerados para os anos de 1985, 1996, 2011 e 2013

Os índices de precisão das classificações - índice de kappa- para os anos 1985, 1996, 2011 e 2013, corresponderam a 0,9968; 0,9986; 0,9972; e 0,9973, respectivamente. Os resultados são considerados excelentes, segundo a qualificação apresentada por Landis e Koch (1977). A tabela 1 descreve os resultados encontrados nas classificações dos períodos avaliados nas classes escolhidas em relação ao tamanho da área em hectares.

Avaliando os resultados encontrados nas classificações (Tabela 1), observa-se uma tendência de aumento de áreas florestadas na área de estudo ao longo do período analisado, bem como aumento de áreas agriculturáveis, que pode estar relacionado com o incentivo fiscal governamental, o melhoramento e modernização da produção, atrelados à diminuição de áreas de Campo. A Lâmina d'água sofreu queda no período avaliado. Esse resultado pode estar associado a forte incidência de chuvas na região no ano de 1985, e posterior estabilização nos anos seguintes.

A classe Areal apresentou diminuição ao longo do tempo. Diversas pesquisas vêm sendo realizadas, além de reflorestamentos e investimentos de empresas privadas, o que corrobora com Suertegaray (1987), ao avaliar esse fenômeno como de ocorrência natural, mas que poderia sofrer influências antrópicas, tanto para seu aumento quanto para a diminuição dessas regiões. 
Tabela 1 - Quantificação do uso e cobertura da terra na Campanha Ocidental-RS, em hectare, entre os anos de 1985, 1996, 2011 e 2013

\begin{tabular}{ccccc}
\hline \multirow{2}{*}{ Classes de uso } & 1985 & 1996 & 2011 & 2013 \\
\cline { 2 - 5 } & Área (ha) & Área (ha) & Área (ha) & Área (ha) \\
\hline Floresta & $328.311,09$ & $420.624,37$ & $437.403,04$ & $440.322,97$ \\
Agricultura & $951.523,02$ & $822.481,69$ & $991.585,94$ & $1.228 .581,67$ \\
Campo & $1.684 .038,70$ & $1.734 .035,50$ & $1.555 .366,89$ & $1.305 .476,14$ \\
Areal & $16.944,75$ & $17.357,61$ & $11.419,22$ & $11.338,15$ \\
Lâmina d'água & $95.954,85$ & $82.273,41$ & $80.997,49$ & $91.053,67$ \\
\hline Total & $3.076 .772,58$ & $3.076 .772,58$ & $3.076 .772,58$ & $3.076 .772,58$ \\
\hline
\end{tabular}

As classes Agricultura e Campo, foram as que obtiveram os maiores valores em hectares em todo o período estudado. Ao longo do tempo, essas duas classes apresentaram relação inversa, onde a medida que as áreas de agricultura aumentaram, as áreas de campo tiveram uma redução considerável. Essa relação é uma tendência mundial, devido as novas fronteiras agrícola, para suprir a necessidade da população.

Transições entre as classes de uso e cobertura da terra

As evoluções do uso e cobertura da terra, obtidas através da linguagem LEGAL, considerando-se três intervalos, 1985 a 1996, 1996 a 2011 e 2011 a 2013, são apresentadas na tabela 2. A tabela 3 indica as taxas percentuais e valor de área (ha), referente aos processos de conversão (redução e expansão) entre as classes durante os períodos.

Tabela 2 - Evolução do uso e Cobertura da Terra, em hectares, e suas respectivas porcentagens entre os anos de 1985-1996, 1996-2011 e 2011-2013 na Campanha Ocidental - RS

\begin{tabular}{lcccccc}
\hline \multirow{2}{*}{ Classes de Uso } & \multicolumn{2}{c}{$\mathbf{1 9 8 5 - 1 9 9 6}$} & \multicolumn{2}{c}{$\mathbf{1 9 9 6 - 2 0 1 1}$} & \multicolumn{2}{c}{$\mathbf{2 0 1 1 - 2 0 1 3}$} \\
\cline { 2 - 7 } & Área (ha) & $\%$ & Área (ha) & $\%$ & Área (ha) & $\%$ \\
\hline Floresta & $92.313,28$ & 28,12 & $16.778,67$ & 3,99 & $2.919,93$ & 0,67 \\
Agricultura & $-129.041,51$ & $-13,6$ & $169.104,24$ & 20,56 & $236.995,73$ & 23,90 \\
Campo & $49.996,81$ & 2,97 & $-178.668,61$ & $-10,30$ & $-249.890,75$ & $-16,07$ \\
Areal & 412,86 & 2,44 & $-5.938,39$ & $-34,21$ & $-81,75$ & $-0,71$ \\
Lâmina d'água & $-13.681,44$ & $-14,3$ & $-1.275,92$ & $-1,55$ & $10.056,18$ & 12,42 \\
\hline
\end{tabular}


Tabela 3 - Conversão entre as classes na Campanha Ocidental do Rio Grande do Sul, nos três períodos de análise, em valores de área (ha)

\section{Entre 1985 a 1996}

\begin{tabular}{cccccc}
\hline De/Para & Floresta & Agricultura & Campo & Areal & Água \\
Floresta & $194.475,51^{*}$ & $54.088,29$ & $75.965,67$ & 422,55 & $3.359,07$ \\
Agricultura & $96.582,06$ & $404.801,46 *$ & $437.175,27$ & $4.637,61$ & $8.326,80$ \\
Campo & $112.847,67$ & $350.971,83$ & $1.205 .688,6 *$ & $3.628,89$ & $10.887,93$ \\
Areal & 778,95 & $3.304,89$ & $5.281,74$ & $7.471,26 *$ & 107,91 \\
Água & $15.995,07$ & $9.587,79$ & $9.474,93$ & $1.230,3$ & $59.666,76 *$ \\
\hline
\end{tabular}

Entre 1996 a 2011

\begin{tabular}{cccccc}
\hline De/Para & Floresta & Agricultura & Campo & Areal & Água \\
Floresta & $244.218,24^{*}$ & $61.242,75$ & $105.351,39$ & 564,93 & $9.053,37$ \\
Agricultura & $72.009,90$ & $451.650,96^{*}$ & $286.475,67$ & $2.114,82$ & $10.205,46$ \\
Campo & $119.450,07$ & $453.397,77$ & $1.150 .148,25^{*}$ & $2.805,93$ & $8.129,16$ \\
Areal & $1.466,37$ & $5.300,46$ & $3.802,23$ & $5.661,45^{*}$ & $1.109,88$ \\
Água & $3.973,32$ & $16.070,94$ & $9.381,24$ & 290,52 & $52.569,45^{*}$ \\
\hline
\end{tabular}

Entre 2011 a 2013

\begin{tabular}{cccccc}
\hline De/Para & Floresta & Agricultura & Campo & Areal & Água \\
Floresta & $278.137,80^{*}$ & $81.546,03$ & $75.025,8$ & 661,50 & $5.527,89$ \\
Agricultura & $61.289,37$ & $660.614,76^{*}$ & $242.009,73$ & $2.716,65$ & $20.952,36$ \\
Campo & $91.302,57$ & $468.886,05$ & $982.233^{*}$ & $1.389,78$ & $11.264,04$ \\
Areal & 779,22 & $2.475,99$ & $1.482,12$ & $6.547,59 *$ & 151,4 \\
Água & $8.488,71$ & $14.931,81$ & $4.636,8$ & 106,20 & $52.779,96 *$ \\
\hline
\end{tabular}

* manutenção

Quanto a evolução do uso e cobertura da terra nos períodos de estudo (Tabela 2 ), destaca-se o considerável aumento de florestas, com $28,12 \%$ entre os anos de 1985 a 1996, 3,99\% entre os anos de 1996 a 2011 e 0,67\% entre o período de 2011 a 2013, indicando que houve preservação, regeneração das florestas e também o reflorestamento dessas áreas. Os resultados obtidos vão de encontro a uma das principais conclusões do Inventário Florestal Contínuo do Rio Grande do Sul realizado em 2001, o qual indicou o aumento da cobertura florestal do Estado (SEMA-RS/UFSM, 2001).

Resultados similares foram encontrado por outros autores (HENDGES et al., 2012; FERRARI, 2008; BENEDETTI et al., 2013) que, atribuem esse aumento ao estabelecimento da regeneração e posterior formação florestal nativa observada, na maioria 
das vezes, ao longo da rede de drenagem, em áreas de maior declividade e, muitas vezes, em áreas anteriormente utilizadas para a atividade agropecuária.

Em relação a Agricultura, no primeiro período analisado (1985-1996), sofreu queda de 13,6\% (Tabela 2). Entre o ano 1981 a 2009, a economia gaúcha apresentou crescimento negativo do PIB por diversas vezes, sendo que, as piores quedas aconteceram em $1990(-6,6 \%)$ e em $1995(-5,0 \%)$, o que seria um dos motivos para a queda da agricultura nesse período. Já na segunda época (1996-2011), houve incremento de $169.104,24$ ha $(20,56 \%)$ das áreas agriculturáveis, possivelmente ocasionada pela abertura de fronteiras agrícolas. No terceiro período, as áreas de agricultura continuaram crescendo com 236.995,73 ha (23,9\%).

A classe Campo, no primeiro período analisado, obteve aumento de 49.996,81 ha $(2,97 \%)$. Esse crescimento pode estar relacionado à diminuição de áreas agriculturáveis nesse primeiro momento. Já no segundo período, houve um decréscimo na classe de $178.668,61$ ha $(10,30 \%)$, e no terceiro período novamente constatou-se queda de $249.890,75$ ha $(-16,07 \%)$. Para Kleinpaul (2005), a queda da classe Campo está relacionada, especialmente, pela conversão dessas áreas em agricultura, sendo o mesmo verificado por Ferrari (2008), Torres (2011) e Furlan (2012).

No período de 1985-1996, a classe Areal sofreu alta de apenas 2,44\%, totalizando incremento de 412,86 ha de novas áreas em processo de arenização (Tabela 2). No segundo período analisado neste estudo, entre 1996-2011, houve queda acentuada nas áreas de arenização, o equivalente a 5.938,39 ha (34,21\%). No terceiro período entre 2011 a 2013, os areais se mantiveram praticamente estáveis apresentando uma queda de apenas 81,75 ha $(0,71 \%)$. Estes resultados podem estar relacionados a utilização de técnicas conservacionistas, tais como o terraceamento para a contenção do fluxo superficial, cobertura do solo por vegetação de rápido crescimento, e também devido aos reflorestamentos com espécies de eucalipto realizados por empresas como a Stora Enso.

Neste estudo, a classe Lâmina D'água, no primeiro período de 1985-1996 (Tabela 2), foi caracterizada por um percentual de queda $13.681,44$ ha $(14,3 \%)$. Esse resultado pode estar associado ao acúmulo de chuvas no ano de 1985 , ao uso dessas áreas alagadas pela agricultura irrigada. Já no período de 1996 a 2011, houve uma pequena queda dessa classe de apenas $1,55 \%$. No último período analisado (2011 2013), houve um acréscimo de $10.056,18$ ha (12,42\%). Essa característica depende basicamente do regime pluviométrico da região e da data da aquisição das imagens, o que faz com que essa classe oscile bastante.

De acordo com a tabela 3, que apresenta a transição entre as classes na Campanha Ocidental do Rio Grande do Sul, nos três períodos de análise, observa-se que a classe Floresta apresentou manutenção de 194.475,51, 244.218,24 e 278.137,80 ha nos períodos 1985-1996, 1996-2011 e 2011-2013, respectivamente. Sendo que nos três períodos analisados a classe que mais contribuiu para o acréscimo da área de Floresta foi a classe Campo, seguido da classe Agricultura. É importante salientar a recuperação dos areais com florestas, com destaque para o segundo período, que obteve acréscimo de 1.466,37 ha.

A Agricultura da região está intensamente associada com a classe Campo como demonstrada na tabela 3. A classe Agricultura que se manteve com 404.801,46 ha no primeiro período avaliado, 451.650,96 ha no segundo período e, com $660.614,76$ ha no terceiro período, teve como principal classe a contribuir com a expansão dessas áreas, a classe Campo. De 1985 a 1996, 350.971,83 ha de áreas de Campo passaram a ser Floresta. Essa área aumentou no período entre 1996 a 2011, em que 453.397,77 ha foram convertidos a Floresta. Entre 2011 a 2013 a área de Campo convertida em Floresta foi ainda maior, correspondendo a 468.886,05 ha. 
A classe Floresta da mesma forma, apresentou acréscimo quanto a sua contribuição para o aumento das áreas de agricultura ao longo dos períodos estudados. As áreas variaram de 54.088,29 ha entre o ano 1985 a 1996, 61.242,75 ha entre 1996 a 2011 e 81.546,03 ha no último período (2011-2013).

Quando comparado a taxa de desmatamento em relação a expansão florestal, evidencia-se que apesar das taxas de desmatamento entre $6,57 \%$ no primeiro período, passando por $6,20 \%$ no segundo e ficando em $6,64 \%$ no terceiro houve um aumento das áreas florestais em relação a sua retirada, pois as taxas de aumento sobre áreas agrícolas foram de 22,96\%, 16,32\% e 13,93\% respectivamente. O mesmo foi encontrado por Lippert (2014) ao analisar as transições florestais do bioma Pampa, constatando que a taxa de expansão foi maior que a taxa de desmatamento entre o período de 2000 a 2012.

Analisando a classe Campo, observou-se a diminuição ao longo dos períodos analisados. Considerando a área de manutenção da classe Campo, que passou de $1.205 .688,6$ ha no primeiro período (1985-1996); $1.150 .148,25$ ha entre 1996-2011 e; 982.233 ha entre 2011- 2013, a manutenção da classe aumentou sua participação em relação a área de campo como um todo. Nesse sentido, dados censitários da pecuária do Rio Grande do Sul (IBGE, 2010), revelam que essa região possui $2.156827,00$ bovinos e $855.198,00$ ovinos, o que explica o aumento em percentual da manutenção dessas áreas de Campo.

A classe que mais sofreu mudanças para o Campo foi a Agricultura com 437.175,27 ha entre os anos de $1985-1996,286.475,67$ ha no período entre 19962011 e 242.009,73 ha no intervalo entre 2011 e 2013. Quanto a classe Areal, em todo o período de estudo, a classe Areal foi influenciada principalmente pelo Campo e Agricultura. No primeiro período, 4.637,61 ha da classe Agricultura e 3.628,90 ha de Campo foram convertidos para a classe Areal. No segundo período (1996-2011), esses valores de conversão para a classe Areal foram de 2.114,82 ha e 2.805,95 ha para as classes de Agricultura e Campo, respectivamente.

No último período analisado (2011-2013), o Campo e Agricultura influenciaram nas mudanças para áreas com Areais, porém destacando-se a agricultura que, foi a classe que mais se transformou, contribuindo com 2.716,65 ha. Esse fato pode ser explicado pela degradação dessas áreas, a saturação dos solos e o completo abandono. Nesse sentido, pode-se afirmar que essas áreas são endêmicas da região, da característica geológica e tipologia de solo, e que as atividades antrópicas contribuem tanto para o seu aumento quanto para diminuição da degradação.

Por fim, observa-se que a maior mudança para classe água ocorreu na classe campo no período de 1985-1996 e nos demais períodos (1996-2011 e 2011-2013) a classe agricultura foi quem mais influenciou as mudanças para água. Entre 1985-1996 a classe água se manteve com $72,46 \%$ do seu total, nos períodos seguintes, se manteve em $64,85 \%$ e $58,21 \%$.

\section{CONCLUSÕES}

O monitoramento das imagens orbitais de média resolução dos satélites Landsat 5 e 8, utilizadas na análise temporal, permitiram quantificar os padrões do processo de uso e cobertura da terra, na microrregião da Campanha Ocidental do Rio Grande do Sul, nos anos de 1985, 1996, 2011 e 2013.

As classes de usos da terra que predominam na Campanha Ocidental do Rio Grande do Sul são Agricultura e Pecuária. Sendo que, ao longo do período de estudo, 
a classe Agricultura apresentou aumento considerável, em contraponto a redução do Campo.

Observou-se que a classe Floresta aumentou em todos os períodos analisados, apresentando um acréscimo em área de $112.011,8$ ha ao longo do período de estudo. A classe que mais influenciou a expansão florestal foi o Campo, da mesma forma, a classe que mais influenciou o desmatamento foi o Campo, seguido da Agricultura.

Em relação aos Areais a expansão dessas áreas deveu-se principalmente a classe Agricultura e a diminuição dessas áreas também foi influenciada pela Agricultura. Destaca-se o incremento de reflorestamento na diminuição de áreas arenizadas. A classe Lâmina d'água foi influenciada predominantemente pelos regimes de chuvas de cada ano de estudo.

\section{REFERÊNCIAS}

ASSOCIAÇÃO BRASILEIRA DE PRODUTORES DE FLORESTAS PLANTADAS. Anuário estatístico ABRAF 2013 ano base 2012 / ABRAF. - Brasília: 2013. Disponível em: <http://www.bibliotecaflorestal.ufv.br/handle/123456789/3887>. Acesso em: 10 jan. 2015.

ASSAD, E. D.; Sano, E. E. Sistema de informações geográficas-Aplicações na agricultura. Brasília: Embrapa/SPI. 2 ed., 1998.

BENEDETTI, A. C. P. Modelagem dinâmica para simulação de mudanças na cobertura florestal das Serras do Sudeste e Campanha Meridional do Rio Grande do Sul. 2010. 166 f. Tese (Doutorado em Engenharia Florestal) - Universidade Federal de Santa Maria, Santa Maria, 2010.

CÂMARA, G.; SOUZA, R. C. M.; FREITAS, U. M.; GARRIDO, J.; MITSUO, F. Spring: Integrating Remote Sensing and Gis by Object-oriented Data Modelling. Computers \& Graphics. v. 20, n. 3, p. 395-403, 1996.

CRÓSTA, A. P. Processamento Digital de Imagens de Sensoriamento Remoto. Campinas: IG, 1992. 170 p.

FERRARI, R. Modelagem de uso e cobertura da terra da Quarta Colônia, RS. 2008. 127 f. Dissertação (Mestrado em Geomática) - Universidade Federal de Santa Maria, Santa Maria, 2008.

FURLAN, M. C. Modelagem dinâmica de uso e cobertura da microbacia do Arrio Grande - RS. 2012. 126 f. Dissertação (Mestrado em Geomática) - Universidade Federal de Santa Maria, Santa Maria, 2012.

HENDGES, E. R.; PEREIRA, R. S.; ANDRES, J. Dinâmica das áreas de floresta nativa no Rio Grande do Sul no período de 1988 a 2020. Ciência Rural, v.42, n.5, p.828833, 2012.

inSTITUTO BRASILEIRO DE GEOGRAFIA E ESTATÍSTICA. Cidades do Brasil. 2010. Disponível em: <http://www.ibge.gov.br/cidadesat/topwindow.htm?1>. Acesso em: 15 out. de 2012.

KAWAKUBO, F. S. Metodologia de classificação de imagens multiespectrias aplicada ao mapeamento do uso e cobertura vegetal na Amazônia: exemplo de caso na região de São Félix do Xingu, Sul do Pará. 2010. 100 f. Tese (Doutorado em Geografia) - Universidade de São Paulo, São Paulo, 2010. 
KLEINPAUL, J. J. Análise multitemporal da cobertura florestal da Microbacia do Arroio grande, Santa Maria, RS. 2005. 80 f. Dissertação (Mestrado em Engenharia Florestal) - Universidade Federal de Santa Maria, Santa Maria, 2005.

LANDIS, J. R.; KOCH, G. G. The measurement of observer agreement for categorical data. Biometrics, v.33, n.1, p.159-174, 1977.

LIPPERT, D.B. Modelagem dinâmica do cenário florestal em unidades de paisagem do Bioma Pampa. 2014. 113 f. Tese (Doutorado em Engenharia Florestal) - Universidade Federal de Santa Maria, Santa Maria, 2014.

MORENO, J. A. Clima do Rio Grande do Sul. Porto Alegre: Secretaria da Agricultura, Diretoria de Terras e Colonização, Secção de Geografia, 1961. 46p.

ROVEDDER, A. P. M. Potencial do Lupinus albescens Hook. \& Arn. para recuperação de solos arenizados do Bioma Pampa. 2007. 145 f. Tese (Doutorado em Ciência do Solo) - Universidade Federal de Santa Maria, Santa Maria, 2007.

SEMA/UFSM-RS. Governo do Estado. Relatório final do inventário florestal contínuo do Rio Grande do Sul. Porto Alegre, 2001, v.1, n.2, 706p.

SOUTO, J. J. P. Deserto, uma ameaça? Estudo dos núcleos de desertificação na fronteira sudoeste do Rio Grande do Sul. Porto Alegre: DRNR, Diretoria Geral, Secretaria de Agricultura. 172 p. 1984.

SUERTEGARAY, D. M. A. A trajetória da natureza. Um estudo geomorfológico sobre os areais de Quaraí/RS. 1987. 243 f. Tese (Doutorado em Geografia) - Departamento de Geografia - Universidade São Paulo, São Paulo. 1987.

SUERTEGARAY, D. M. Deserto Grande do Sul: controvérsia. 2 ed. Porto Alegre: Ed. Da Universidade/UFRGS, 1998. 130p.

TORRES, D. R. Análise multitemporal do uso da terra e cobertura florestal com dados dos satélites LANDSAT e ALOS. 2011. 96 f. Dissertação (Mestrado em Engenharia Florestal) - Universidade Federal de Santa Maria, Santa Maria, 2011.

Recebido em março de 2016

Revisado em julho de 2016

Aceito em julho de 2016 